\title{
ERG and VEP follow-up study in children with Leber's congenital amaurosis
}

\begin{abstract}
Purpose Our prospective clinical and electrophysiological study of children suspected of Leber's congenital amaurosis (LCA) was aimed to follow-up the course of their visual dysfunction.

Methods Electroretinography (ERG) and visual evoked potentials (VEP) to white flash stimulation were simultaneously recorded in 9 children at least twice.

Results The first flash ERG and flash VEP recordings were performed when children were 3-17 months old (mean age 7.6 months). Flash ERG was not recordable in 8 children; flash VEP to binocular stimulation could not be detected in 3, was delayed in 2, attenuated in 2 , both attenuated and delayed in 1 , and without evident abnormality in 1 of the 9 children. On the last examination (mean age 33.8 months) flash VEP activity was recordable in all children, while flash ERG was recordable in 1. Electrophysiological followup (mean duration 26.2 months) showed no deterioration of flash VEP in 8 children. Conclusion In children of LCA simultaneous recording of flash ERG and flash VEP in alert children was helpful to indicate the nature of the visual problem for diagnostic and followup purposes.
\end{abstract}

Key words Children, Electroretinography, Leber's congenital amaurosis, Visual evoked potentials, Visual electrophysiology

Leber's congenital amaurosis (LCA) is a congenital rod-cone disorder, associated with very poor vision from birth. The acuity is usually markedly reduced to counting fingers or worse; infrequently, it can be slightly better. Roving eye movements or nystagmus appear very early; fundi are usually normal in infancy but later show attenuated vessels and chorioretinal pigmentary abnormalities. The prevalence of LCA has been reported to range from $10 \%$ to $18 \%$ in schools for the blind in Europe. It has an autosomal recessive mode of inheritance. $^{1}$
Electroretinography plays an important role in diagnosing LCA. The electroretinogram (ERG) is reported to be unrecordable in most cases; in a few only it may be detectable, though very attenuated..$^{2-10}$ On the other hand, flash visual evoked potentials (VEPs) are reported to be detectable in many children with LCA. ${ }^{11}$ In children with no visual following, simultaneous recording of retinal and visual cortical activity has been shown to provide a more complete evaluation of the visual functional state than recording the ERG only. ${ }^{12}$ Further, it has been shown that skin ERG recordings are sensitive enough to allow a reliable evaluation of most forms of retinal dysfunction associated with a large variety of disease entities. ${ }^{13}$

Several follow-up studies have been focused on the ocular and systemic features of LCA. ${ }^{11,14-16}$ In a majority of children with LCA the degree of visual dysfunction appeared stable in terms of visual acuity, although fundoscopic changes appeared to be mildly progressive. Two studies have examined ERG follow-up in children with LCA and showed that the flash ERG was non-recordable in the vast majority of cases. ${ }^{11,15}$

Flash VEP follow-up was not reported, yet it is expected to be more helpful in studying the dynamics of visual dysfunction in children with LCA because it was recordable in $44 \%$ of cases. ${ }^{11}$ Our aim was to serially record ERGs and VEPs in children suspected of LCA, and to assess the degree of change in visual dysfunction with time. Electrophysiology and clinical status were followed up in 9 children suspected of LCA. ERG and VEP activity to bright white, red, and dim blue flashes, as well as to $30 \mathrm{~Hz}$ and pattern-reversal stimulation, were recorded. The patient data were compared with those obtained in age-matched controls.

\section{Patients and methods}

Nine children ( 5 boys, 4 girls) were suspected of LCA according to the criteria of Lambert et al.: unrecordable or highly attenuated ERG, severe visual deficit from infancy and absence of other specific retinal or multisystemic disorder. ${ }^{1}$

The study was approved by the Slovene Research and Medical Ethics Committee.
J. Brecelj

Institute of Clinical Neurophysiology University Medical Centre Ljubljana, Slovenia

\section{B. Stirn-Kranjc}

Eye Clinic

University Medical Centre Ljubljana, Slovenia

Jelka Brecelj, PhD Institute of Clinical Neurophysiology University Medical Centre Zaloška 7, 1525 Ljubljana Slovenia

Tel: +386 $61316-152$ or +386 61 13-13-206 Fax: +386 61 302-771 e-mail: jelka.brecelj@uikn.mf.uni-lj.si

Supported by the Ministry of Science and Technology of the Republic of Slovenia, grant no. J3-7021

Received: 10 February 1998 Accepted in revised form: 23 October 1998 
Thorough neurological and ophthalmological examinations were also carried out to exclude patients with neurodegenerative or metabolic diseases. All had computed tomography (CT) and/or MRI of the head. Electrophysiological testing was carried out at least on two occasions. The recording procedures followed the Great Ormond Street Hospital protocol. ${ }^{13}$ In alert children without pupil dilatation ERGs were detected by conventional silver-silver chloride cup electrodes attached to the lower eyelid and referred to Fz. VEP electrodes were applied to the posterior scalp: the midline electrode was placed at $\mathrm{Oz}(10 \%$ of the nasion-to-inion separation) and the two lateral electrodes to either side of the midline electrode ( $20 \%$ of the rightto-left mastoid distance, approximately $4 \mathrm{~cm}$ ). All electrodes were referred to a common midfrontal reference $(\mathrm{Fz})$.

ERG and VEP activity to bright white, red, and dim blue flashes, as well as to $30 \mathrm{~Hz}$ and pattern-reversal stimulation, were recorded. Testing in all conditions was binocular. A Grass PS22 photic stimulator (with filters) was used for delivering bright white flashes (intensity setting 4), bright red flash (red filter; peak transmission from $670 \mathrm{~nm}$, intensity setting 4), dim blue flash (blue filter; peak transmission $470 \mathrm{~nm}$, intensity setting 1) and $30 \mathrm{~Hz}$ white flash stimulation (intensity setting 1). All flash testing was performed under fully darkened conditions (scotopic conditons).

Checkerboard stimuli were presented on a television screen subtending $25^{\circ}$ horizontally and $20^{\circ}$ vertically. The check sizes were $6^{\circ}, 3^{\circ}, 100^{\prime}$ and $49^{\prime}$. The luminance was 120 and $2 \mathrm{~cd} / \mathrm{m}^{2}$ for the white and black checks, respectively.

The stimulation rate of the flash and pattern was $2 \mathrm{~Hz}$. The analysis time for both the ERG and VEP recordings was $250 \mathrm{~ms}$, and the bandpass 1-250 Hz. Between 50 and 100 responses were averaged and repeated at least twice. ERG and VEP findings in LCA children were compared with those in age-matched normal children.

\section{Results}

\section{Clinical examination}

Children were first examined at between 3 and 17 months of age. They all had nystagmus (roving eyes in 2 children) and poor vision. None had a family history of LCA or a sibling with the disease.

The main ophthalmological findings of the first and the last examinations are presented in Table 1. The children's outer and anterior eye segments were unremarkable; their optic media were clear. At the first examination they were all mildly photophobic and had sluggish pupils. Seven of them poked their eyes. The optic disc was not atrophic in all 9 cases, but appeared hypoplastic in 5 (cases 3, 5, 6, 8, 9). There was a clinical ophthalmoscopic impression of about a $10-20 \%$ smaller disc diameter, excluding the optic effect of higher refractive error. Retinal vascular attenuation was moderate in cases 1 and 6 . The macular reflex was clear in three children (cases 5,8,9), while in others it was only slightly abnormal (not so clear), without extra granularity and hyper- or hypopigmentation. Peripheral retinal pigment mottling - a sign of mild retinal dystrophy - was noticed in 4 children (cases 1, 2,3,8). No other specific pathology, such as bone spicules or large dystrophic areas or macular coloboma, was found.

Visual acuity was poor, ranging from light perception up to 0.01 in the better eye. All the children were hypermetropic (with or without hypermetropic

Table 1. Clinical findings in Leber's congenital amaurosis (first, last examination)

\begin{tabular}{|c|c|c|c|c|c|c|c|c|}
\hline $\begin{array}{c}\text { Case } \\
\text { no. }\end{array}$ & $\begin{array}{c}\text { Age } \\
\text { (months) }\end{array}$ & $\begin{array}{l}\text { Optic nerve } \\
\text { pallor }\end{array}$ & $\begin{array}{l}\text { Right vascular } \\
\text { attenuation }\end{array}$ & $\begin{array}{l}\text { Macular } \\
\text { reflex }\end{array}$ & $\begin{array}{c}\text { Retinal } \\
\text { dystrophy }\end{array}$ & $\begin{array}{l}\text { Visual acuity in } \\
\text { better eye }\end{array}$ & $\begin{array}{c}\text { Refractive } \\
\text { error }\end{array}$ & $\begin{array}{l}\text { Systemic } \\
\text { disorder }\end{array}$ \\
\hline \multirow[t]{2}{*}{1} & 7 & \pm & \pm & \pm & + & LP & +6.0 & Heart \\
\hline & 37 & - & \pm & \pm & - & 0.02 & +6.0 & Heart \\
\hline \multirow[t]{2}{*}{2} & 17 & - & - & \pm & + & LP & +6.50 & - \\
\hline & 63 & - & \pm & \pm & + & 0.03 & +7.0 & - \\
\hline \multirow[t]{2}{*}{3} & 5 & - & - & \pm & + & LP & $+4.50=+2.0 / 90$ & CNS \\
\hline & 34 & - & - & + & + & 0.04 & $+4.0=+1.0 / 90$ & - \\
\hline \multirow[t]{2}{*}{4} & 8 & - & - & \pm & - & LP & +4.50 & - \\
\hline & 54 & - & \pm & + & \pm & 0.02 & +3.0 & - \\
\hline \multirow[t]{2}{*}{5} & 6 & - & - & + & - & LP & +3.50 & Skin, CNS \\
\hline & 29 & - & \pm & + & \pm & 0.01 & +2.50 & Skin, CNS \\
\hline \multirow[t]{2}{*}{6} & 9 & - & \pm & \pm & - & LP & +5.50 & - \\
\hline & 12 & - & \pm & \pm & - & 0.01 & +5.50 & - \\
\hline \multirow[t]{2}{*}{7} & 3 & - & - & \pm & - & LP & +6.50 & - \\
\hline & 27 & - & \pm & + & - & 0.04 & +5.50 & - \\
\hline \multirow[t]{2}{*}{8} & 6 & - & - & + & + & LP & +7.50 & CNS \\
\hline & 14 & - & \pm & + & \pm & 0.01 & +6.50 & - \\
\hline \multirow[t]{2}{*}{9} & 7 & - & - & + & - & 0.01 & $+3.50=+3.50 / 90$ & - \\
\hline & 34 & - & \pm & + & - & 0.04 & $+2.0=+2.50 / 90$ & - \\
\hline
\end{tabular}

- , not present; \pm , moderate abnormality; + , present.

CNS, central nervous system; LP, light perception. 
astigmatism), with refractive errors ranging from +3.5 to +7.5 dioptres. They were included in a blind or low vision rehabilitation programme.

CT scans and/or MRI of the head were normal in 6 children. In 1 (case 3 ) there was evidence of an enlargement of the ventricles, while in 2 cases slight atrophy of the brain was shown (cases 5,8 ). None of the children had hearing loss, but all showed evidence of mild neurodevelopmental delay on the first examination. No syndrome or association with retinal dystrophy could be found.

On the last clinical examination 3-46 months later (mean follow-up 26.2 months), the nystagmus was slightly reduced in its frequency and amplitude in all the children. Four children had enophthalmos (severe eye poking), 4 were esotropic and 1 exotropic. Photophobia was less severe in 5 children, but none had conspicuous problems navigating in the dark. The fundoscopic appearance did not show much deterioration either, especially of the macula, which mostly retained its reflex. There was a very moderate progression of retinal vascular attenuation in most cases and slightly more peripheral retinal pigment mottling in 2 children (cases 4 , $5)$, while in case 1 there was no longer a sign of mild retinal dystrophy. Preferential looking and/or with Cambridge acuity cards showed very poor vision in all the children (ranging from light perception to 0.04). Two children (cases 4,9 ) were able to name colours of toys and pencils at a distance of $15 \mathrm{~cm}$; however, their visual acuity was insufficient to allow any clinical colour testing. Refractive errors did not change much during follow-up (ranging +2.0 to 7.0 dioptres).

All the children had caught up the delay in their neurodevelopment, most likely thanks to the effective low vision rehabilitation programme and appropriate central nervous system development. None of them had seizures during follow-up, or any systemic disorders which are known to be or could be associated with retinal dystrophies. Only 1 child (case 5) still had some motor problems and seborrhoeic dermatitis; another (case 1) had an open foramen ovale and mild tricuspid valve insufficiency.

\section{ERG and VEP findings}

All nine children suspected of LCA were tested electrophysiologically at least twice. ERG and VEP data are presented in Table 2. For the first recording, infants

Table 2. ERG and VEP findings in children with Leber's congenital amaurosis

\begin{tabular}{|c|c|c|c|c|c|c|c|c|c|c|c|c|c|c|c|}
\hline \multirow{3}{*}{$\begin{array}{c}\text { Case } \\
\text { no. }\end{array}$} & \multirow{3}{*}{$\begin{array}{c}\text { Age } \\
\text { (months) }\end{array}$} & \multicolumn{3}{|c|}{ White flash } & \multicolumn{3}{|c|}{ Red flash } & \multicolumn{3}{|c|}{ Blue flash } & \multicolumn{2}{|c|}{$30 \mathrm{~Hz}$} & \multirow{2}{*}{\multicolumn{3}{|c|}{$\begin{array}{c}\text { Pattern reversal } \\
\text { VEP }\end{array}$}} \\
\hline & & \multirow[t]{2}{*}{ ERG } & \multicolumn{2}{|c|}{ VEP } & \multirow[t]{2}{*}{ ERG } & \multicolumn{2}{|c|}{ VEP } & \multirow[t]{2}{*}{ ERG } & \multicolumn{2}{|c|}{ VEP } & \multirow[t]{2}{*}{ ERG } & \multirow[t]{2}{*}{ VEP } & & & \\
\hline & & & $\mathrm{ms}$ & $\mu \mathrm{V}$ & & $\mathrm{ms}$ & $\mu \mathrm{V}$ & & $\mathrm{ms}$ & $\mu \mathrm{V}$ & & & $\mathrm{ms}$ & $\mu \mathrm{V}$ & \\
\hline \multirow{3}{*}{1} & 7 & - & - & - & & & & & & & & & & & \\
\hline & 11 & - & - & - & & & & & & & & & & & \\
\hline & 37 & - & 93 & 3.7 & - & 93 & 2.3 & - & 124 & 2.3 & - & - & & & \\
\hline \multirow[t]{4}{*}{2} & 17 & - & - & - & & & & & & & & & & & \\
\hline & 26 & * & - & - & & & & & & & & & & & \\
\hline & 47 & - & 97 & 2.4 & & & & & & & & & & & \\
\hline & 63 & - & 100 & 2.3 & - & 116 & 2.4 & * & 110 & 6.4 & - & - & - & - & $\left(49^{\prime}\right)$ \\
\hline \multirow[t]{4}{*}{3} & 5 & - & - & - & & & & & & & & & & & \\
\hline & 10 & - & 160 & 13.2 & - & 187 & 5.0 & - & 164 & 7.0 & & & & & \\
\hline & 11 & - & 152 & 9.4 & - & 121 & 1.0 & - & 148 & 9.0 & & & & & \\
\hline & 34 & - & 175 & 10.4 & - & 161 & 7.0 & - & 173 & 6.5 & - & - & 187 & 7.6 & $\left(49^{\prime}\right)$ \\
\hline \multirow[t]{4}{*}{4} & 8 & - & 104 & 3.4 & & & & & & & & & & & \\
\hline & 15 & - & 103 & 1.3 & & & & & & & & & & & \\
\hline & 33 & - & 100 & 2.5 & - & 99 & 3.6 & - & 99 & 3.8 & - & - & & - & $\left(6^{\circ}\right)$ \\
\hline & 54 & - & 96 & 3.8 & - & 99 & 3.6 & - & 133 & 3.3 & - & - & & - & $\left(49^{\prime}\right)$ \\
\hline \multirow[t]{3}{*}{5} & 6 & - & 106 & 2.1 & & & & & & & & & & & \\
\hline & 9 & - & * & $*$ & & & & & & & & & & & \\
\hline & 29 & - & 107 & 1.6 & - & - & - & - & - & - & - & - & & & \\
\hline \multirow[t]{2}{*}{6} & 9 & - & 94 & 9.8 & - & 100 & 6.5 & - & 95 & 7.2 & - & - & & & \\
\hline & 12 & - & 87 & 10.6 & - & 90 & 4.3 & - & 87 & 9.0 & * & - & - & - & $\left(3^{\circ}, 49^{\prime}\right)$ \\
\hline \multirow[t]{3}{*}{7} & 3 & - & 172 & 17.2 & - & 214 & 5.5 & - & 169 & 15.2 & & & & & \\
\hline & 9 & - & 166 & 2.8 & & & & & & & & & & & \\
\hline & 27 & - & & & - & & & - & & & - & & & & \\
\hline \multirow[t]{2}{*}{8} & 6 & - & 143 & 5.0 & & & & & & & & & & & \\
\hline & 14 & - & 142 & 3.5 & - & 181 & 2.5 & * & 170 & 9.9 & & & - & - & $\left(3^{\circ}\right)$ \\
\hline \multirow[t]{5}{*}{9} & 7 & * & 136 & 1.4 & & & & & & & & & & & \\
\hline & 10 & * & 125 & 11.8 & & & & & & & & & & & \\
\hline & 17 & + & 145 & 6.3 & - & 127 & 5.0 & + & 137 & 8.5 & & & & & \\
\hline & 24 & + & 155 & 13.8 & & & & & & & & & - & - & $\left(1^{\circ}, 49^{\prime}\right)$ \\
\hline & 34 & + & 141 & 2.1 & - & 143 & 18.3 & + & 143 & 11.2 & - & - & - & - & $\left(49^{\prime}\right)$ \\
\hline
\end{tabular}

Limits of abnormality: white flash, $>135 \mathrm{~ms}<5.0 \mu \mathrm{V}$ (first), $>115 \mathrm{~ms}<10.0 \mu \mathrm{V}$ (last); red flash, $>108 \mathrm{~ms}<16.1 \mu \mathrm{V}$; blue flash, $>132 \mathrm{~ms}$ $<3.6 \mu \mathrm{V}$. Abnormal values are printed in bold.

- , not recordable; + , recordable ERG; *artefact $\left(6^{\circ}, 3^{\circ}, 1^{\circ}, 49^{\prime}\right)$ check sizes tested. 
HEALTHY CHILD

6 months

ERG

Right

Left

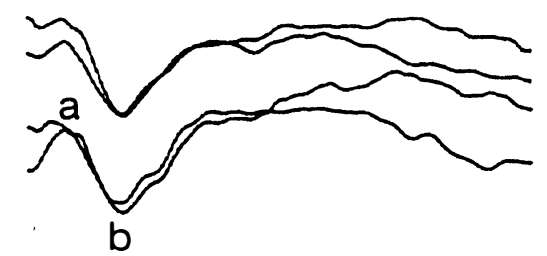

VEP
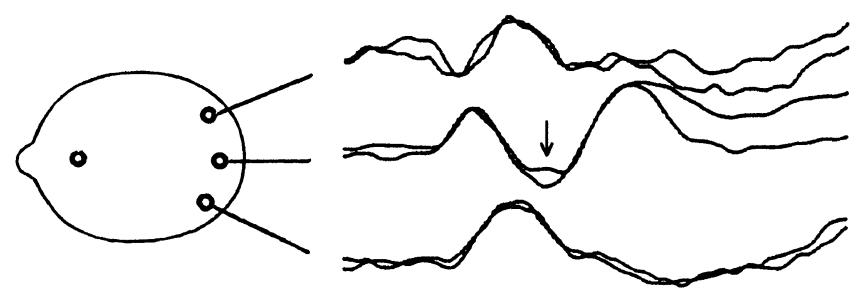

0

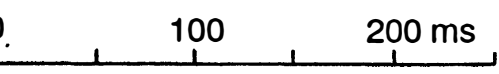

LEBER'S AMAUROSIS

6 months

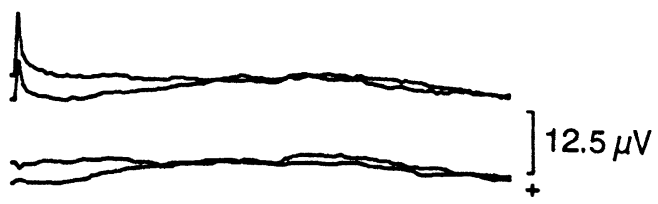

Fig. 1. ERG and VEP recordings in a child suspected of LCA compared with the recordings in an age-matched control. Stimuli were white photopic flashes. Stimulus artefact is seen in the right eye ERG trace. Note that in the control child the $a$-and $b$-waves of the ERG are labelled, and the positive wave of the VEP is marked with an arrow.

were tested with a bright white flash under scotopic conditions. The flash ERG was not detectable in 8 children. The flash VEP to binocular stimulation was not detectable in 3 children (cases 1, 2, 3), was attenuated in 2 (cases 4,5 ), did not show evident abnormality in one
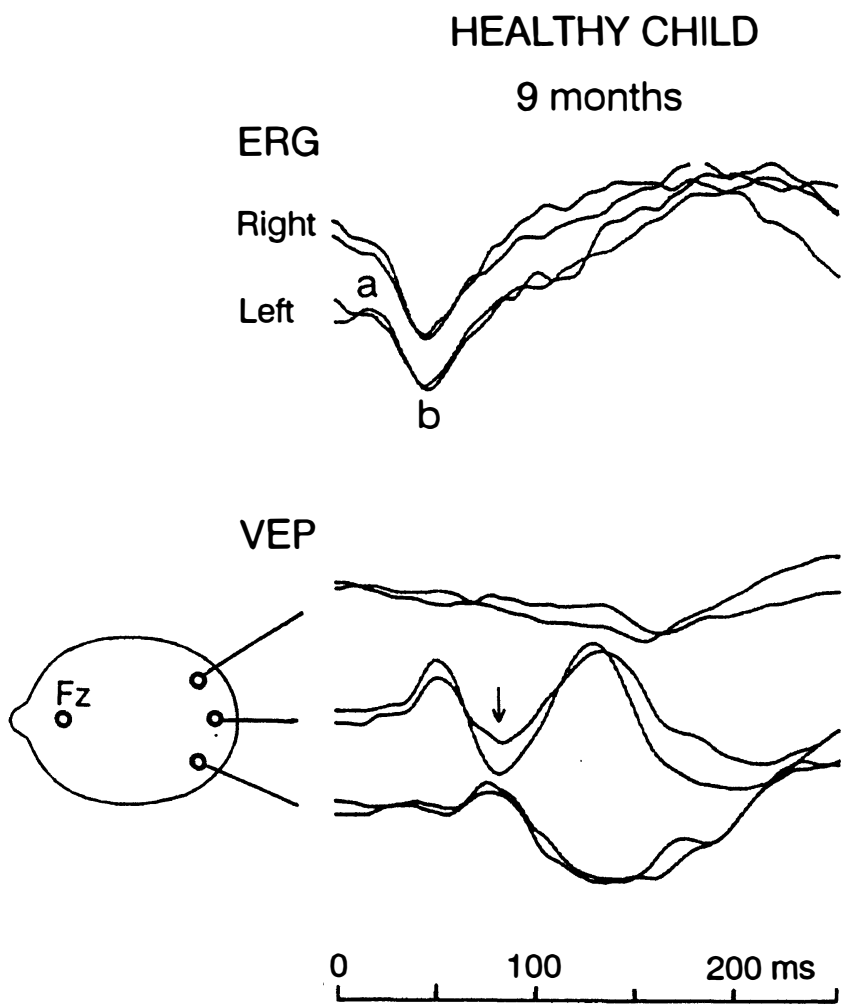

(case 6), was delayed in 2 (cases 7,8), and was both attenuated and delayed in 1 child (case 9). Typical recordings to bright white flash stimulation in a 6-monthold child with suspected LCA and in his age-matched control are presented in Fig. 1. The patient's flash ERG

\section{LEBER'S AMAUROSIS \\ 9 months}
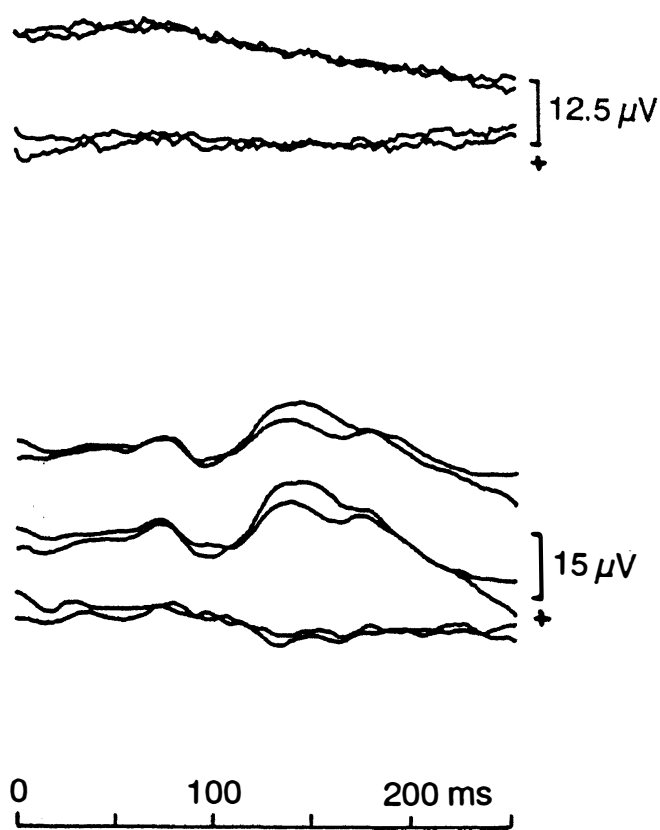

Fig. 2. ERG and VEP recordings in a child suspected of LCA compared with an age-matched control. Stimuli were white photopic flashes. Note that in the control child the $a$ - and b-waves of the ERG are labelled, and the positive wave of the VEP is marked with an arrow. 
HEALTHY CHILD

ERG

$\mathrm{RE}$

White flash

LE

(n)

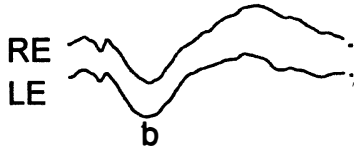

Blue flash

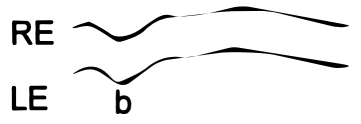

Red flash

Pattern

(check 49')
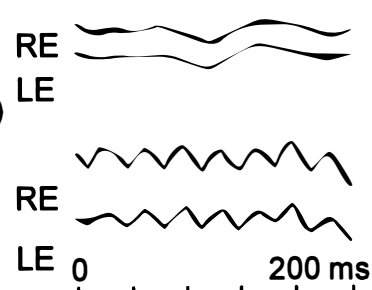

VEP
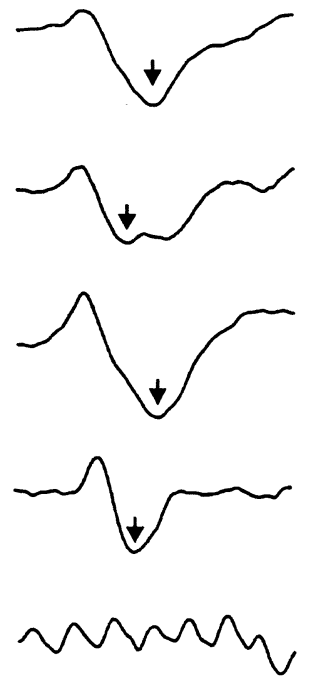

$200 \mathrm{~ms}$
LEBER'S AMAUROSIS

ERG
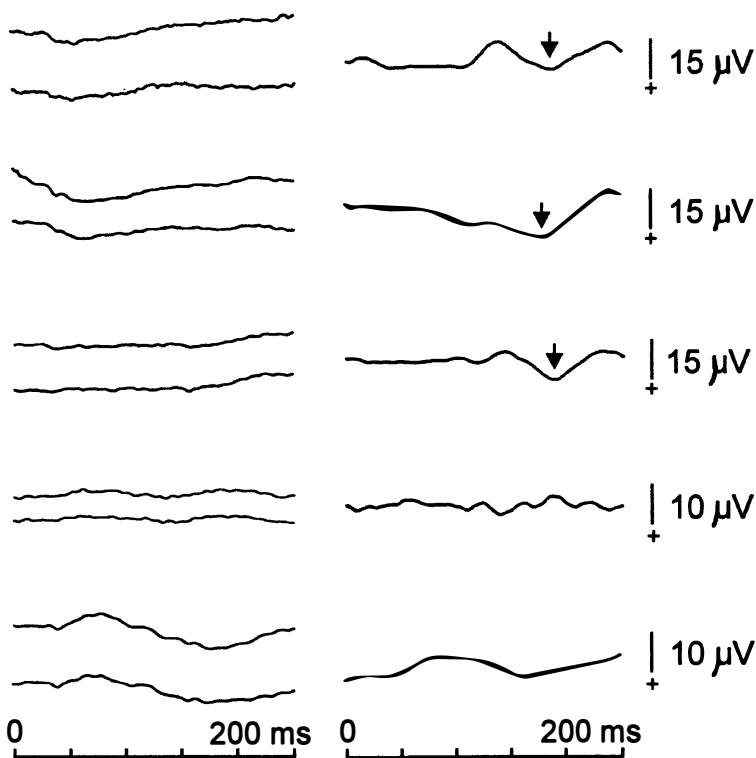

Fig. 3. ERG and VEP follow-up recordings of a 5-year-old girl suspected of LCA and an age-matched control. In the control child the b-waves of the flash ERGs are labelled, and the positive waves of flash and pattern reversal VEPs are marked with an arrow. In the child suspected of LCA attenuated and prolonged flash VEPs are marked with an arrow.

and VEP were extinguished. In another 9-month-old child ERG activity was also extinguished, but flash VEP was not significantly attenuated (Fig. 2).

On subsequent recordings the test protocol was extended, and bright red, dim blue, $30 \mathrm{~Hz}$ white flash flicker, and pattern-reversal stimulation were also performed. Fig. 3 presents the follow-up recordings of a 5 -year-old girl suspected of LCA and her age-matched control. No reliable ERG was detectable to white flash, red flash and $30 \mathrm{~Hz}$ stimuli. On the other hand, attenuated VEPs were seen to white, red and blue flash stimuli.

None of the children suspected of LCA had a detectable ERG to bright red flash. Dim blue flash stimulation evoked definite activity, which was not attenuated below the limit of age-matched controls, in one suspected LCA child (case 9). At the cortical level, VEP activity was recordable in 7 children suspected of LCA to both red and blue flash stimulation. It was markedly attenuated $(p<0.05$; red flash - mean amplitude in children with LCA was $5 \mu \mathrm{V}$ and mean amplitude of age-matched healthy children was $35.0 \mu \mathrm{V}$; blue flash - mean amplitude in children with LCA was $5.5 \mu \mathrm{V}$ and mean amplitude in age-matched healthy children was $25.6 \mu \mathrm{V}$ ).

Pattern reversal VEP, which was detectable only in 1 child, was significantly delayed (case 3 ). No children had detectable ERG or VEP to $30 \mathrm{~Hz}$ flicker stimulation.

\section{ERG and VEP follow-up}

ERGs and VEPs to bright white flash stimulation on the first and the last recordings are presented in Figs. 4-6. Patients' recordings were compared with those of the age-matched controls. At the first recording, the age range of the patients was 3-17 months (mean 7.6 months), and 4-19 months (mean 7.7 months) for controls. At the last recording the age range of the patients was 12-63 months (mean 33.8 months), while that of the controls was 11-63 months (mean 31.8 months). Flash ERG activity was not detectable in 8 children suspected of LCA on the first recording; for case 9 the recording was unsatisfactory. On the last examination the ERG to bright white flash was detected only in case 9: although the b-wave was reduced, this was not below $10.7 \mu \mathrm{V}$ (-2 SD limit of normality) (Fig. 4).

Flash VEP activity was detectable in 6 of the 9 children suspected of LCA on the first examination, and in all of them on the last examination (Fig. 5). Mean flash VEP amplitudes of children suspected of LCA were significantly attenuated compared with normal controls on the last examination $(p=0.054)$.

Follow-up recordings (after 3-46 months; mean follow-up 26.2 months) showed no deterioration of flash VEP activity (Figs. 5,6). Between the first and the last recordings the Mann-Whitney test showed no significant difference in mean amplitudes $(p=0.775)$ and latencies $(p=0.775)$ to white flash stimulation. Individual recordings presented in Table 2 show that VEP to white flash stimulation improved in 3 children, remained stable 
White flash ERG

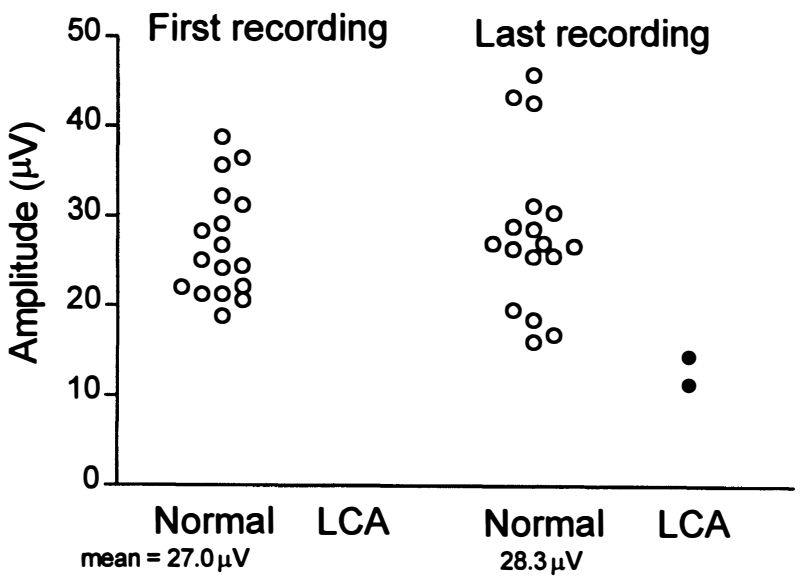

Fig. 4. Comparison of ERG b-wave amplitudes to white flash stimulation in children suspected of LCA (LCA) and their age-matched controls (normal). In the first and last recordings individual values are presented in circles (eyes) and mean values in numbers.

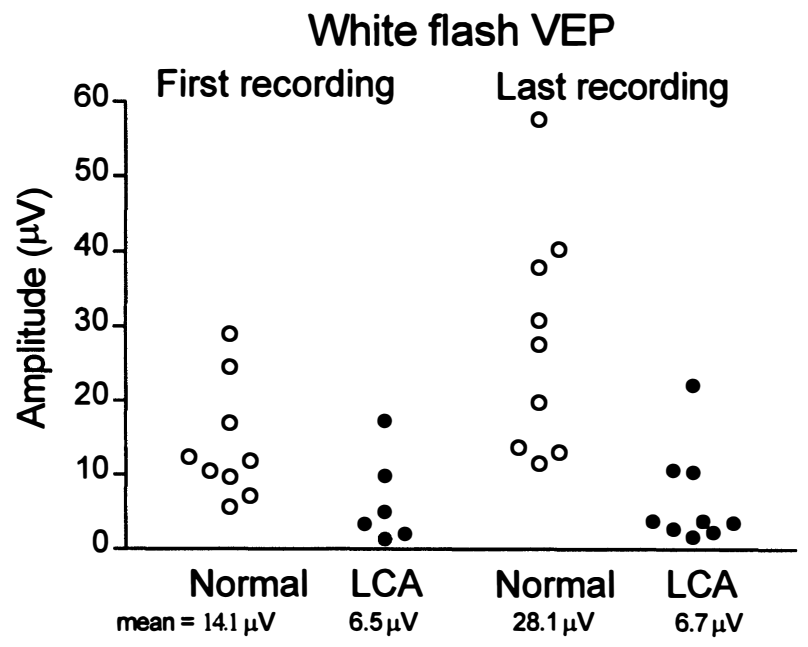

Fig. 5. Comparison of VEP amplitudes of the positive wave to white flash stimulation in children suspected of LCA (LCA) and their agematched controls (normal). In the first and last recordings individual values are presented in circles and mean values in numbers.

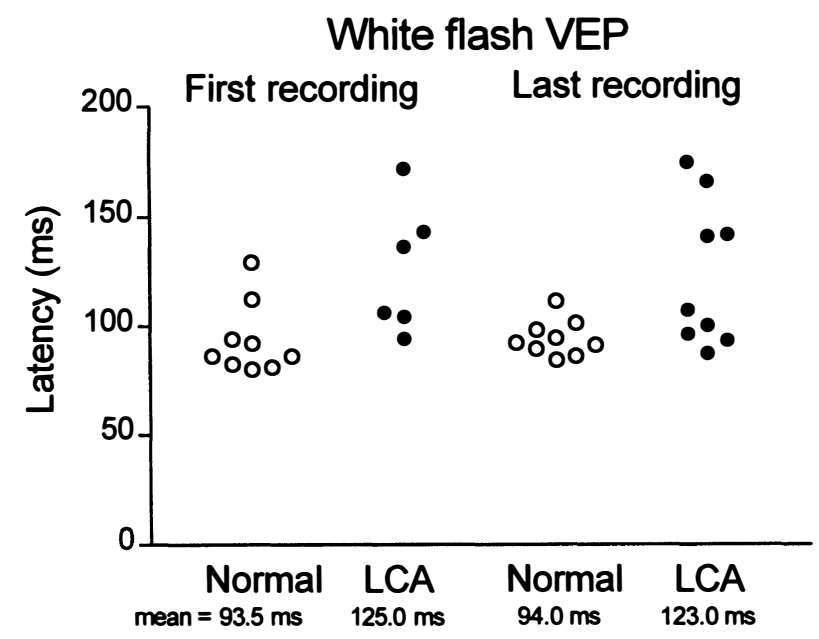

Fig. 6. Comparison of VEP latencies of the positive wave in children suspected of LCA and age-matched controls on the first and last recordings. On the first recording VEP was not measurable in 3 LCA children. Individual values are presented in circles and mean values in numbers.

in 5 and worsened in 1 . In 3 children (cases $1,2,3$ ) flash VEP activity was present on the last examination but not on the first. In 4 children (cases 4, 5, 6, 8) flash VEP amplitude and latency changes were not significant. Also in 1 child (case 9) flash VEP activity remained stable after the second recording at 10 months. However, flash VEP worsened in 1 child (case 7). A decrease in amplitude $(>80 \%)$ was observed outside the normal range (less than $3 \mu \mathrm{V})$.

\section{VEP latency measurements}

Latencies of the main positive VEP component in the children suspected of LCA and the normal controls are presented in Fig. 6 . The main positivity to bright white flash stimulation may exceed the upper normal value
(2.5 SD limit of normality) in 3 children on the first examination (cases $7,8,9$ ) and 4 children on the last examination (cases $3,7,8,9$ ). Compared with normal controls, mean flash VEP latencies were significantly prolonged in children suspected of LCA on the first (Mann-Whitney test, $p=0.0001$ ) and the last ( $p=0.0448$ ) examinations.

The recordings from 1 child (case 3; Fig. 6) illustrate the waveform changes that might lead to latency changes. At 5 months, flash VEP was unrecordable, but at 10 and 11 months a high-amplitude positive wave was present at around $160 \mathrm{~ms}$, and thereafter, at the age of 34 months, two positive waves were recordable: a prominent positive wave at around $180 \mathrm{~ms}$, and an attenuated positive wave at around $100 \mathrm{~ms}$. 


\section{Discussion}

Combined ERG and VEP recording is a simple yet powerful means of assessing visual pathway function in young children. ${ }^{17-19}$ Our findings of simultaneous ERG and VEP recordings are in accordance with previous reports claiming that in the majority of patients with LCA the mixed rod-cone ERG to bright white flash was extinguished while in many of them flash VEP was recordable. ${ }^{4,11}$ Therefore, our serial flash ERG was not helpful in the assessment of the évolution of eye changes or the progressive course, since most children had no measurable flash ERG throughout. On the other hand, VEP activity to bright white flash was recordable in twothirds of the children on the first examination. On the last examination, flash VEP activity was also recordable in 3 children whose VEP activity was not recordable on the first examination (cases 1, 2, 3). Thus, flash VEP was found to be helpful in obtaining additional information on preserved retinal function. A study relevant to our findings has shown that the stimulus luminance at which the response reached half its maximum amplitude was lower for the flash VEP than for the flash ERG. The higher sensitivity of the flash VEP is due to the magnification of the foveal contribution to the flash VEP. $^{20}$

In the majority of children suspected of LCA no deterioration of VEP activity to bright white flash could be observed in the individual records. Flash VEP findings were stationary in 5 children, but seemed to improve in 3 children and to deteriorate in 1.

Improvements (seen as absent flash VEP activity on the first examination but recordable flash VEP activity on following recordings) may be attributed to maturation of the central visual pathway. Flash VEP deterioration was observed as significant amplitude reduction ( $>80 \%)$. Also, between the first (mean age 7.6 months) and the last (mean age 33.8 months) examinations mean flash VEP amplitudes and latencies were not significantly different.

In our study ERG activity to bright white flash stimulation was not recordable in any of the 8 children suspected of LCA at the first examination (aged 3-17 months) or at follow-up (mean duration of follow-up, 26.2 months). Only in the ninth child (case 9), in whom it was technically not possible to make flash ERG recordings at the first examination, could flash ERG be detected at subsequent examinations. Other follow-up studies have shown that the flash ERG is non-recordable in the vast majority of cases. The flash ERG was found to be unrecordable in 42 of 43 children in the original and follow-up assessments (mean duration of follow-up 6.4 years). ${ }^{11}$ Similarly, the flash ERG was unrecordable in all 18 LCA children both at a mean age 3.6 months and after a 1 year interval. ${ }^{15}$

We also performed dim blue flash stimulation (under scotopic conditions) to identify disorders predominantly affecting the rod photoreceptors, and red flash and $30 \mathrm{~Hz}$ stimulation to identify disorders predominantly affecting the cone photoreceptors. Under these conditions it has been shown that electrophysiological findings in LCA, achromatopsia and congenital stationary night blindness differ. ${ }^{1,9,13}$ In one child (case 9) we found a wellpreserved b-wave to dim blue flash and to bright white flash (also under scotopic conditions), while the ERG was unrecordable to red flash and $30 \mathrm{~Hz}$ stimulation. A similar electrodiagnostic picture may be seen in achromatopsia. However, this child had ERG activity to white flash stimulation also preserved under photopic conditions, and on the last ophthalmological examination she could name colours. Therefore, it seems that the possibility of distinguishing between rod and cone dysfunction by means of skin electrodes using blue and red filters should be further explored by correlating more clinical data with ERG parameters.

In the largest series of 43 LCA children presented by Lambert et al. ${ }^{11}$ flash VEP was, however, considerably reduced (group mean amplitude $4 \mu \mathrm{V}$, compared with the normal mean of $22 \mu \mathrm{V}$ ). Similarly, flash VEP activity in our group of children was reduced at both the first (group mean amplitude $6.5 \mu \mathrm{V}$, compared with the agematched normal mean of $14.1 \mu \mathrm{V}$ ) and last examinations (group mean amplitude $6.7 \mu \mathrm{V}$, compared with the agematched normal mean of $28.1 \mu \mathrm{V}$ ). However, in 1 child (case 6) flash VEP activity was well preserved while the flash ERG was not recordable. The same was seen also on subsequent recording at 12 months, and recently at 45 months. Such an electrophysiological picture can be seen in Joubert syndrome and retinitis pigmentosa. ${ }^{13}$ In this child cerebellar vermis hypoplasia was not confirmed by

\section{LEBER'S AMAUROSIS}

Case 3

10 months

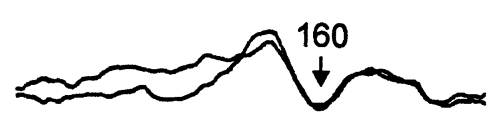

$200 \mathrm{~ms}$

\section{1 months}

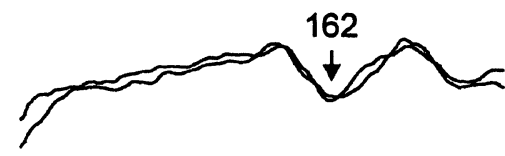

$200 \mathrm{~ms}$

\section{4 months}

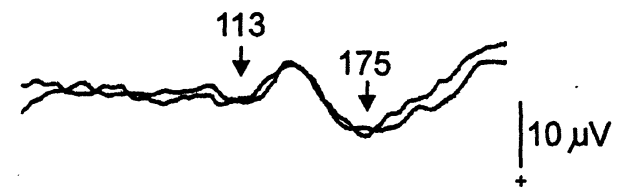

Fig. 7. Flash VEP recordings in a child suspected of LCA at 10,11 and 34 months. On the first two recordings only one positive wave at around $160 \mathrm{~ms}$ was clearly seen (arrow). Later, an early positive wave (around $100 \mathrm{~ms}$ ) also emerged (arrow). 
CT scan, which excluded Joubert syndrome. In a recent study, normal flash VEPs and an unrecordable flash ERG were also found in LCA children. ${ }^{15}$

In our study the VEP latency of the positive wave to white flash stimulation exceeded the upper normal value in 3 children suspected of LCA on the first examination and in 4 at the last examination. In 1 child, interestingly, only one (late) positive component was prominent in the first recording. Subsequently, an early positive component emerged (Fig. 7). Therefore, when interpreting VEP latency in LCA children, maturation of the VEP waveform should also be considered.

All our children had very low visual acuity levels (0.01-0.04) and recordable flash VEP on the last examination. This is in accordance with the previous findings, according to which flash VEP was recordable in LCA children whose visual acuity was at the level of light perception or hand movement. ${ }^{4,9,11}$ On the other hand, pattern VEP was detectable in 1 of our 6 children whose attention could be directed towards the stimulus pattern. Also, only in 2 of 43 LCA children was VEP detectable to pattern-reversal stimulation, with the $7^{\circ}$ checks. ${ }^{11}$ In the case of LCA presented by Apkarian and Spekreijse, ${ }^{21}$ a 14-month-old child yielded clear onset VEP responses to $110 \mathrm{~min}$ and 9 min checks but the response disappeared at 6 min checks. It seems that this finding may not be characteristic of LCA. However, a recent study by Saunders et al. ${ }^{22}$ showed that patternonset stimuli produce larger, better-quality VEP than pattern reversal when nystagmus is present.

In our group of children suspected of LCA mild fundoscopic changes (retinal vascular attenuation, peripheral retinal pigment mottling), high refractive error, nystagmus, eye poking and poor vision were important for diagnosis, but were non-specific for clinical and electrophysiological outcome. There was no correlation between the results of electrophysiological testing and the clinical examinations. Those with better vision did not tend to have better flash VEP. Also, in case 1 pigmentary changes were noticed on the first but not on the last examination, while in case 2 were pigmentary changes noticed on both occasions. However, in both children (cases 1,2) flash VEP was absent on the first examination but present on the last examination.

It may be concluded that on the grounds of the clinical examination all our 9 children were diagnosed as having LCA. Electrophysiological findings were in accordance with the diagnosis of LCA in 8 children, while in 1 LCA or any other rod/cone dystrophy remains to be confirmed. The follow-up revealed no deterioration of the flash VEP activity in the majority of children with LCA.

We would like to thank Dr Tony Kriss, The Eye Department, Hospital for Sick Children, London, for his valuable comments; Mrs Tatjana Vidmar and Mrs Nevenka Zlatnar for their help in the electrophysiological recordings; Mr Nacek Zidar for preparations of figures; and Mr Milos Kogej for editing.

\section{References}

1. Lambert SR, Taylor D, Kriss A. The infant with nystagmus, normal appearing fundi, but an abnormal ERG. Surv Ophthalmol 1989;34:173-86.

2. Franceschetti A, Dieterlé P. Importance diagnostique et prognostique de l'électrorétinogramme (ERG) dans les dégénérescences tapéto-rétiniennes avec rétrécissement du champ visuel et héméralopie. Confin Neurol 1954;14:184-6.

3. Dekaban AS. Mental retardation and neurologic involvement in patients with congenital retinal blindness. Dev Med Child Neurol 1972;14:436-44.

4. Vaizey MJ, Sanders MD, Wybar KC, Wilson J. Neurological abnormalities in congenital amaurosis of Leber: review of 30 cases. Arch Dis Child 1977;52:399-402.

5. Nickel B, Hoyt CS. Leber's congenital amaurosis: is mental retardation a frequent associated defect? Arch Ophthalmol 1982;100:1089-92.

6. Foxman SG, Heckenlively JR, Bateman JB, Wirtschafter JD. Classification of congenital and early onset retinitis pigmentosa. Arch Ophthalmol 1985;103:1502-6.

7. Schroeder R, Mets MB, Maumenee IH. Leber's congenital amaurosis: retrospective review of 43 cases and a new fundus finding in two cases. Arch Ophthalmol 1987;105:356-9.

8. Gelbart SS, Hoyt CS. Congenital nystagmus: a clinical perspective in infancy. Graefes Arch Clin Exp Ophthalmol 1988;226:178-80.

9. Good PA, Searle AET, Campbell S, Crews SJ. Value of the ERG in congenital nystagmus. Br J Ophthalmol 1989;73:512-5.

10. Weiss AH, Biersdorf WR. Visual sensory disorders in congenital nystagmus. Ophthalmology 1989;96:517-23.

11. Lambert SR, Kriss A, Taylor D, Coffey R, Pembrey M. Follow-up and diagnostic reappraisal of 75 patients with Leber's congenital amaurosis. Am J Ophthalmol 1989;107:624-31.

12. Kriss A, Russell-Eggitt I. Electrophysiological assessment of visual pathway function in infants. Eye 1992;6:145-53.

13. Kriss A, Jeffrey B, Taylor D. The electroretinogram in infants and young children. J Clin Neurophysiol 1992;9:373-93.

14. Heher KL, Traboulsi EI, Maumenee IH. The natural history of Leber's congenital amaurosis: age-related findings in 35 patients. Ophthalmology 1992;99:241-5.

15. Casteels I, Spileers W, Demaerel P, Casaer P, De Cock P, Dralands L, Missotten L. Leber congenital amaurosis: differential diagnosis ophthalmological and neuroradiological report of 18 patients. Neuropediatrics 1996;27:189-93.

16. Fulton AB, Hansen RM, Mayer L. Vision in Leber congenital amaurosis. Arch Ophthalmol 1996;114:698-703.

17. Brecelj J, Stirn-Kranjc B. Electrophysiologic evaluation of the visual pathway in children: case reports. Doc Ophthalmol 1992;79:313-23.

18. Ikeda H. Electrodiagnosis of the primary afferent visual system: past, present and future. Zdrav Vestn 1993;62 (Suppl 1):57-65.

19. Kriss A. Visual electrophysiological testing of young children. Zdrav Vestn 1993;62(Suppl 1):85-90.

20. Brigell M, Marchese AL. The luminance-amplitude function of simultaneously recorded flash visual evoked potential and electroretinogram. Clin Vis Sci 1993;8:41-6.

21. Apkarian $P$, Spekreijse $H$. The use of the electroretinogram and visual evoked potentials in ophthalmogenetics. In: Desmedt JE, editor. Visual evoked potentials. Amsterdam: Elsevier, 1990.

22. Saunders KJ, Brown G, McCulloch DL. Pattern-onset visual evoked potentials: more useful than reversal for patients with nystagmus. Doc Ophthalmol 1998;94:265-74. 